\title{
A LUTA PELA UNIVERSALIDADE DAS POLÍTICAS PÚBLICAS DE TRANSPORTE
}

\section{Lúcio Gregori}

Universidade de São Paulo (USP)

\begin{abstract}
A LUTA PELA UNIVERSALIDADE DAS POLÍTICAS PÚBLICAS DE TRANSPORTE
Resumo: O presente artigo trata da questão da universalidade dos transportes na mobilidade urbana, entendendo-a como uma questão política. Analisa os aspectos da formulação histórica do modelo existente. Aborda, para tanto, aquilo que considera questões centrais nessa análise, quais sejam, a tarifa, as formas de contratação dos serviços, a ação do poder público, o subsídio, entre outros. Trata, ainda da questão da universalização do sistema de transporte coletivo urbano não apenas sob a perspectiva de sua gratuidade, mas mostrando as ações necessárias para evitar as distorções de vários tipos que o modo de produção pode impor mesmo com a universalidade.

Palavras-chave: Mobilidade, transportes coletivos, subsídio, tarifa, concessão, automóvel, usuário, universalidade.
\end{abstract}

\section{THE STRUGGLE FOR UNIVERSALITY OF PUBLIC POLICIES OF TRANSPORT}

Abstract: This article deals with the issue of universality of transport in urban mobility, understanding it as a political issue. Analyzes the historical aspects of the formulation of the existing model. Addresses, therefore, what it considers central issues of this analysis, namely, the rate, forms of contracting services, government action, subsidy, among others. It deals also with the issue of universal urban transportation system not only from the perspective of their gratuity, but showing the necessary actions to prevent distortions of various kinds that the mode of production can impose even with universality. Key words: Mobility, collective transport, subsidy, fare, concession, car, user, universality. 


\section{INTRODUÇÃO}

A universalidade em saúde, educação, segurança pública já existe a tempo considerável, mas é curioso observar que inexiste a universalidade no chamado transporte público e que o nível de subsídio no Brasil é baixíssimo. Na figura abaixo pode-se ver uma comparação entre os níveis de subsídio em diversos países em função do salário médio (Figura 1).

\section{Fiqura 1 - Tempo é dinheiro}

\section{TEMPO É DINHEIRO}

Quantos minutos o cidadão precisa trabalhar para pagar uma passagem de ônibus

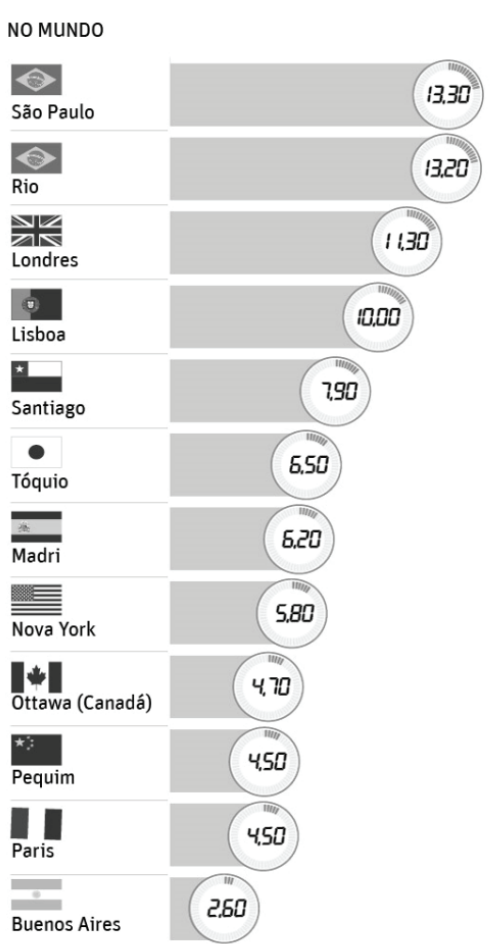

Fonte: MAGALHÃES, G. Tarifa de ônibus em SP e Rio está entre as mais caras do mundo, diz estudo. Folha de São Paulo, São Paulo, 16 jan. 2015. Disponível em:<http://www1.folha.uol.com.br/ cotidiano/2015/01/1575811-tarifa-de-onibus-emsp-e-rio-esta-entre-as-mais-caras-do-mundo-dizestudo.shtml. Acesso em: 1 jan. 2016.

Então se o nível de subsídio de São Paulo, Rio e Fortaleza (13,60 min de tempo de trabalho) fossem os mesmos de Paris, as tarifas de ônibus seriam de $R \$ 1.20$ e $R \$ 1,15$ e $R \$ 0,90$ respectivamente, ao invés de $R \$ 3,50, R \$ 3,40$ e $\mathrm{R} \$ 2,95$. Uma diferença considerável.

Somente em 15/09/2015 foi promulgada pelo Congresso Nacional a emenda constitucional que torna o transporte um direito social, nos termos do artigo sexto da Constituição Federal (CF). Mas ainda é um princípio constitucional que necessitará de outras leis complementares para se chegar, por exemplo, a fortes subsídios ou universalidade no acesso a esse direito.
Isso só foi possível em decorrência das manifestações de junho de 2013, pois essa proposta estava paralisada na Câmara Federal desde o início de 2011, quando foi apresentada pela deputada Luiza Erundina. Observe-se que foi no seu governo na prefeitura de São Paulo que, em 1990, foi proposto o projeto denominado Tarifa Zero, que justamente propunha a universalidade no acesso aos ônibus municipais.

Essa situação nos transportes públicos, quando mais de $80 \%$ da população vive em cidades, nos remete a indagar sobre as razões desse atraso e quais significados aí estão envolvidos.

Estamos diante do que se pode chamar uma longa construção histórica a partir da aldeia, onde a mobilidade necessária era muito pequena, mas se torna indispensável à medida que a indústria, comércio e serviços se ampliam e exigem a crescente mobilidade dos moradores das cidades para acessá-los e garantir seu funcionamento.

Mas nos termos de nosso modo de produção capitalista e com as tradições segregadoras de nossa sociedade, a forma de organizar a mobilidade, associada à indústria imobiliária, além de servir aos desígnios do chamadosetor produtivo, serve, também, para concretizar a acessibilidade diferenciada às diversas partes da cidade, em função de classe social,gênero, raça etc. Além disso, as mulheres andam amedrontadas com assédios decorrentes de veículos superlotados, assim como travestis e gays. E crianças podem se sentir ameaçadas ou assustadas em coletivos muito lotados (DINIZ, 2013).

Tudo isso passa pelo modelo de transferência da responsabilidade pela mobilidade ao Estado, ao mesmo tempo em que é percebida uma nova frente de negócio e se estabelece uma forma de realização do transporte coletivo através de contratos com o setor privado. O transporte coletivo é entendido como um serviço resolvido a mercado, mediante o pagamento do serviço prestado. A tarifa a ser paga pelo usuário, então, é fundamental para que a mobilidade atenda ou não a função múltipla acima citada.

Além disso, a mobilidade física é fundamental para a chamada mobilidade social, que permite, que o cidadão caminhe de uma classe social para outra no que diz respeito à renda, ao nível educacional, ao acesso a bens e serviços culturais e de saúde, bem como ao consumo em geral. Ou seja, naquilo que numa sociedade de classes como a nossa, se chama simplificadamente de subir na vida, melhorar de vida ou de qualidade de vida. Em outras palavras, quanto maior a mobilidade física, maiores as possibilidades, embora limitadas por outros fatores, de ascensão social e vice-versa, ou dito de outro modo, a mobilidade física é elemento constitutivo da mobilidade e status social.

O índice do número de viagens/dia mostra 
isso claramente. Veja-se as tabelas a seguir que mostram as diferentes mobilidades segundo gênero, escolaridade e classes de renda.

Tabela 1 - Mobilidade na cidade de São Paulo por gênero - 2012

\begin{tabular}{l|l|l}
\hline Masc. & Fem. & Variação \% * \\
\hline 2,31 & 2,07 & 11,59 \\
\hline
\end{tabular}

Fonte: SÃO PAULO. Governo do Estado. Secretaria de Transportes Metropolitanos. Diretoria de Planejamento e Expansão dos Transportes Metropolitanos. Pesquisa de mobilidade 2012 da Região Metropolitana de São Paulo: Sistema das Informações - Pesquisa Domiciliar. São Paulo, 2013. Disponível em:<http://www.metro.sp.gov.br/metro/ arquivos/mobilidade-2012/relatorio-sintesepesquisa-mobilidade-2012.pdf $>$. Acesso em: 1 jan. 2016.

Nota: * variação $\%=($ mobilidade masculina - mobilidade feminina) / mobilidade feminina.

Tabela 2 - Mobilidade na cidade de São Paulo por escolaridade - 2012

\begin{tabular}{l|l|l|l|l}
\hline & \multicolumn{4}{|c}{$\begin{array}{c}\text { Mobilidade em São } \\
\text { Paulo (viagens/pessoa/dia) }\end{array}$} \\
\hline $\begin{array}{l}\text { Grau de } \\
\text { Instrução }\end{array}$ & Coletivo & Motorizado & $\begin{array}{c}\text { Não } \\
\text { motorizado }\end{array}$ & Total \\
\hline $\begin{array}{l}\text { Analfabeto } \\
\text { I.ograu } \\
\text { incompleto }\end{array}$ & 0,62 & 0,97 & 0,80 & 1,77 \\
\hline $\begin{array}{l}\text { 1.o grau } \\
\text { complete/ } \\
\text { 2.o grau } \\
\text { ncompleto }\end{array}$ & 0,84 & 1,35 & 0,84 & 2,19 \\
\hline $\begin{array}{l}\text { 2.o grau } \\
\text { caompleto/ } \\
\text { superior } \\
\text { incompleto }\end{array}$ & 1,09 & 1,95 & 0,54 & 2,49 \\
\hline $\begin{array}{l}\text { Superior } \\
\text { completo }\end{array}$ & 0,68 & 2,31 & 0,53 & 2,85 \\
\hline \begin{tabular}{l} 
Fonte: (SÃO PAULO, 2013). \\
\hline
\end{tabular} & & & & \\
\hline
\end{tabular}

Tabela 3 - Mobilidade na cidade de São Paulo por escolaridade - outubro 2012

\begin{tabular}{c|c|c|c|c}
\hline \multirow{2}{*}{$\begin{array}{c}\text { Classe de } \\
\begin{array}{c}\text { Renda } \\
\text { em reais }\end{array}\end{array}$} & \multicolumn{4}{|c}{ Mobilidade em São } \\
\cline { 2 - 5 } Paulo (viagens/pessoa/dia) \\
\hline Até 1244,00 & 0,65 & 0,87 & 0,80 & 1,73 \\
\hline $\begin{array}{c}\text { De 1244,00 } \\
\text { a 2488,00 }\end{array}$ & 0,88 & 1,26 & 0,78 & 2,04 \\
\hline $\begin{array}{c}\text { De 4976,00 } \\
\text { a 9330,00 }\end{array}$ & 0,72 & 2,12 & 0,52 & 2,63 \\
\hline $\begin{array}{c}\text { Acima de } \\
\mathbf{9 3 3 0 , 0 0}\end{array}$ & 0,57 & 2,35 & 0,44 & 2,79 \\
\hline Fonte: (SÃO PAULO, 2013). & & & \\
\hline
\end{tabular}

A construção histórica passa, então, pela elaboração do arcabouço jurídico, econômico e na configuração no imaginário dos usuários, de um modelo que atenda os desígnios amplos da mobilidade acima citados e, sobretudo, transfira para esse imaginário a convicção de que a mobilidade de cada um é de sua própria responsabilidade e, por ela, deve pagar.

Vamos analisar alguns elementos que constituem essa construção histórica, a saber, os transportes coletivos, a tarifa, o usuário e o automóvel.

\section{TRANSPORTES COLETIVOS}

Originalmente, as indústrias e a atividade rural garantiam a presença dos trabalhadores no local de produção através da localização destes junto às unidades de produção ou da lavoura. As vilas operárias ou industriais e as colônias são exemplos disso. O morar muito perto do trabalho também era possível, dadas as dimensões menores das cidades e da menor rotatividade da mão de obra.

Como se disse, à medida que cresce a atividade econômica, sobretudo nas cidades, tornase inviável o modelo das vilas e da proximidade moradia-trabalho, possíveis nas aldeias ou nas cidades nascentes. Torna-se necessário um serviço de transportes coletivos.

Este serviço é percebido como negócio de boa proporção e o Estado, a quem é atribuída a responsabilidade de garanti-lo, o transfere mediante contrato, em geral sob a forma de concessão, para o setor privado operá-lo. E este só o faz enquanto negócio.

Os transportes coletivos se constituem, porém, num mercado peculiar. Algo como um mercado monopsônio, onde só há um comprador. Não se consegue estabelecer a concorrência nos transportes coletivos como no mercado de bens de consumo, por exemplo.

Dadas duas empresas que concorrem pelos mesmos passageiros num certo trajeto, como esses não são multiplicáveis, uma delas não prosperará. Pior, as empresas disputarão os passageiros onde há mais concentração deles, e onde eles forem mais escassos, não haverá transporte ofertado.

Daí a figura da concessão em que só uma empresa opera determinada região ou um conjunto de linhas da cidade, e tem de ofertar lugares tanto para onde houver alta densidade de usuários como para onde esta for baixa, ou seja, tem de operar linhas mais rentáveis e linhas menos rentáveis.

Por sua vez, um sistema de transportes sob concessão e viabilizado como negócio, ou seja, serviço realizado à mercado pela tarifa, terá a qualidade proporcional à capacidade de pagamento de seus usuários. Se estes são, no geral, aqueles que têm menor renda na sociedade, a qualidade do serviço pode ficar comprometida. A menos que não se cobre a totalidade do custo de um serviço melhor 
ou seja, haja subsídio, que, como se viu, no Brasil é baixíssimo.

A concessão em geral é dada por prazos longos de 20, 25 ou mais anos, para que o empresário sinta segurança no seu investimento e por ele se interesse, segundo o entendimento estabelecido, mas é, de fato, um prazo muito longo, se considerarmos a dinâmica das cidades nesse período.

A concessão pressupõe, no caso dos transportes, um território de exclusividade e um modo de garantir a rentabilidade do negócio, chamado de equilíbrio econômico-financeiro do contrato de concessão. A tarifa desempenha o papel de tal garantia. É como uma fiadora do contrato.

$\mathrm{Na}$ concessão, diferentemente de outros contratos de serviços públicos, há um envolvimento do concessionário no serviço em si, já que este poderá ser maisou menos lucrativo, dependendo das linhas, se rentáveis ou não, das especificações do desempenho do serviço etc. Ele estará diretamente envolvido e interessado na determinação da tarifa.

Nos contratos de obras e outros serviços públicos, o empresário executa a obra, presta um serviço ou fornece um equipamento e aí cessa seu envolvimento. Não Ihe interessa, genericamente falando, envolver-se na destinação dos mesmos. Não the diz respeito quem vai arcar com os valores que lhe foram pagos pelo poder público. Se a obra ou equipamento são rentáveis ou não, também não Ihe diz respeito. Não é o que ocorre na concessão de transportes públicos, seja pelo vinculo tarifário, seja porque, como já dito, existem diferentes possibilidades de rentabilidade em função das linhas a operar, padrão de serviço etc.

O empresário concessionário de transportes coletivos, nesse caso, reage como em qualquer outro negócio. Seu comportamento racional é o de buscar o maior lucro possível. Caso contrário corre o risco de ver seu negócio perecer.

Uma primeira contradição nas concessões e fator, dentre outros, de permanente tensão na relação poder concedente-concessionário é a tarifa única. Como consequência desta, as linhas menos rentáveis, aquelas que têm menor quantidade de passageiros por distância percorrida, serão inconvenientes para o concessionário. Este buscará as linhas mais rentáveis, curtas e com muito sobe/desce de passageiros. Também procurará transportar o máximo de passageiros com a menor frota possível, o que influi na determinação de rotas e índices de desempenho e renovação de frota, a qual será postergada o quanto possível para não elevar os investimentos. Todas essas questões influirão na determinação da tarifa e, junto com ela, serão fonte de permanente tensão entre o poder concedente e os concessionários. Muitas empresas estatais surgiram para regular tal mercado monopsônio e acabaram por ficar com a maior parte das linhas não rentáveis. De certo modo elas ajudaram a viabilizar as concessionárias. Poucas resistiram.

As considerações aqui feitas se referiram, sobretudo, aos ônibus. Eles constituem o modo coletivo que transporta maior número de passageiros nas cidades brasileiras. Outras considerações poderão ser feitas com relação a outros modos. Todavia, ter-se-á sempre a questão dos transportes coletivos olhado, sobretudo, pelo prisma de negócio, quando se tratar da figura da concessão ou similar.

\section{A TARIFA}

A tarifa é a garantia econômico-financeira do negócio. Na prática ela torna o uso dos transportes coletivos privativo dos que a pagam. Daí ser impróprio classificá-los de transportes públicos por analogia, por exemplo, à educação e saúde públicas. São, na realidade, transportes de acesso público, mas de uso privado.

A tarifa é um preço público, já que o Estado é o detentor do serviço prestado pelo setor privado. Assim, é a autoridade estatal, via poder executivo, que fixa a tarifa. Isso lhe confere um conteúdo de manipulação política, que pode ser feita em função de conjunturas político eleitorais, momento dos reajustes etc. Qualquer cidade brasileira já assistiu a essa quase comédia. Retenção de reajustes próximo de eleições seguidos de reajustes abusivos, reajustes em períodos de férias para evitar protestos etc.

A tarifa acaba tornando-se um feitiço. Para o usuário, que assume a responsabilidade pelo seu deslocamento e pelo dever de pagá-la no ato de utilização do serviço; para o empresário, pela sua dependência para obter os lucros de seu negócio e pior, pela dependência de uma determinação do poder concedente, que fixa seu valor, tendendo a gerar uma relação ambígua com o Estado; e para o poder concedente e para os políticos, por todo poder que ela possui. Para o bem ou para o mal. Para os que não são usuários, a tarifa sempre existiu e é natural que assim seja. Assim, a tarifa é feitiço para uns e banalidade para outros. Mas sempre presente.

Ao longo do tempo, foi criado o necessário arcabouço jurídico para viabilizar o negócio dos transportes coletivos e dar-lhe robustez: por meio da garantia do equilíbrio econômico-financeiro do contrato pela tarifa; com a distinção entre serviço público e de utilidade pública, garantindo a cobrança e a segregação de uso entre os que pagam e os que não pagam; com a distinção entre serviço divisível e indivisível, donde a cobrança de tarifa e não de taxa. A tarifa é como um imposto não progressivo e pode ser reajustada a qualquer momento com vigência imediata, sem os entraves e limitações dos demais impostos, como o princípio da anualidade por exemplo.

Vários aperfeiçoamentos e propostas surgiram ao longo do tempo como decorrência de 
impasses e das lutas políticas e sociais; o valetransporte, que se limita a certa porcentagem do salário e só garante o deslocamento residênciatrabalho; a meia passagem ou gratuidade para os estudantes; as propostas sobre desoneração via renúncia fiscal de certos insumos do transporte coletivo, e o bilhete único. Todos visando o barateamento do deslocamento, mas ainda insuficientes para torná-lo efetivamente acessível a todos. Mas a tarifa está sempre presente como fiadora do contrato de concessão.

Cabe observar que os casos de renúncia fiscal apontados acima, visando diminuição da tarifa dentro do regime de concessão, em geral significam diminuição de arrecadação. Em algum lugar do orçamento público esse recurso a menor deverá ser cortado, caso não haja compensação da perda. Pode ser que o usuário de transporte coletivo acabe pagando numa outra compensação o eventual ganho que teve na tarifa, ou perca qualidade em algum outro serviço público que teve corte por diminuição de receita.

O subsídio cruzado, frequentemente usado nas gratuidades, onera o passageiro pagante para subsidiar as gratuidades e o bilhete único por viagem num sistemade remuneração do operador por passageiro transportado que é muito frequente. Onera o contratante, pois o bilhete é único, mas o pagamento ao empresário é por catraca rodada (ZILBOVICIUS; GREGORI, 2013).

Para se ter um transporte com qualidade muito superior à capacidade de pagamento dos usuários, é necessário separar radicalmente o custo do serviço do preço cobrado. O empresário é contratado como numa obra pública, como se a frota fosse fretada. Daí por diante o empresário não estará mais envolvido no serviço. Não lhe importará se a linha é rentável ou não. Coletará a tarifa, se houver, e a entregará ao detentor do serviço, o poder público. Este determinará a tarifa estabelecendo o grau de subsídio. Assim a tarifa deixará de ser a fiadora do equilíbrio de um contrato, como na concessão. $E$ o serviço poderá ter uma qualidade muito superior à capacidade de pagamento dos usuários, desde que subsidiado. Essa modalidade de contratação foi implantada em São Paulo em janeiro de 1992, após aprovação da Lei $n^{\circ} 11037$, de 25 de julho de 1991. A nova modalidade foi denominada de Municipalização dos Ônibus. A frota foi uniformizada em sua identidade visual como sendo um serviço da Prefeitura e os resultados foram consideráveis: a frota aumentou $25 \%$ em menos de um ano, após estar congelada por mais de dez anos; o número de passageiros por metro quadrado na hora de pico caiu pela metade, de 12 para 6 passageiros; o tempo de espera caiu em até mais de $12 \%$ em algumas regiões; a tarifa média de 1992 foi de US\$ 0,43 (quarenta e três centavos da cotação do dólar de então). E o prazo de cada contrato de frota foi reduzido até o máximo de dez anos (SÃO PAULO, 1992).

Finalmente a tarifa pode ter um resultado perverso quanto ao estímulo do uso do transporte individual motorizado, que, como se viu, conduz a uma inviabilidade. Dependendo do valor da tarifa, o usuário migrará para o transporte individual, sobretudo dadas as condições de financiamento a longoprazo dos automóveis e motos e a retenções do preço da gasolina para combater a inflação. Ele o perceberá como relativamente mais barato e confortável e, estimulado pela propaganda e pela má qualidade dos transportes coletivos, o verá como mais conveniente. Adicionalmente sentirá maior liberdade de movimentação e horários de uso.

Por isso se afirma que o transporte coletivo precisa ser o mais semelhante possível ao transporte individual no que se refere ao conforto, à flexibilidade de horários, partição da viagem e escolha de trajeto e espaço viário disponível e exclusivo. Ou seja, ele tem de ser de boa qualidade, abundante, rápido e em rede para permitir diversas viagens/dia e barato. Finalmente, a tarifa-feitiço é, também, um estopim de revoltas. Além das sistemáticas manifestações que ocorrem anualmente quando de seu reajuste, podemos destacar manifestações de grande porte que entraram para a história; a Revolta do Vintém em 1879 no Rio, o quebra-quebra de 1947 em São Paulo quando mais de um terço da frota de ônibus e bondes foi depredada, a paralisação dos bondes no Rio em 1956, a Revolta das Barcas em Niterói em 1959, a Revolta do Buzu em Salvador em 2003, que dá origem ao aparecimento de movimentos sem organização vertical, a Revolta da Catraca em Florianópolis em 2004 e as Jornadas de Junho de 2013, que culminaram com a estrondosa vitória pela remoção do aumento tarifário em mais de 100 cidades brasileiras!

Com essa característica da tarifa, podese perceber todos os significados da mobilidade e o quanto ela é vista, nos momentos de reajuste tarifário, pelo ângulo de seu impedimento e nas formas de controle e segregação no viver na cidade.

\section{O USUÁRIO}

Ao longo do tempo o usuário, através do aparato ideológico e de valores, introjeta todos os conceitos relativos ao transporte coletivo como um negócio que, como tal, tem que ser pago por ele, supostamente seu principal beneficiário. Introjeta a ideia de que os deslocamentos são de sua responsabilidade, perdendo de vista a origem do interesse e a necessidade das indústrias, estabelecimentos comerciais e de serviços terem força de trabalho e consumidores em seus estabelecimentos. Ou seja, o usuário perde a ideia de que o transporte é, sobretudo, fundamental para os empregadores e comerciantes. Exemplo disso é o dia de greve nos transportes. Os usuários 
vão disputar a pouca oferta, ficarão ansiosos por correrem o risco de atraso ou de não chegarem aos postos de trabalho. As televisões mostrarão a sôfrega disputa por lugares nos poucos veículos disponíveis.

Se a greve tiver duração um pouco mais prolongada, indústrias, comércio e serviços começarão a se manifestar para o seu urgente término. Irão sentir seus efeitos. A cidade para de funcionar, os congestionamentos aumentam. A aparência é de caos. Fica evidente o papel estratégico dos transportes coletivos e da mobilidade.

Se houvesse plena consciência do seu significado para a cidade como um todo, o usuário, no geral, ao ser informado sobre a greve, poderia voltar para casa e aguardar o seu fim. Afinal não lhe cabe nenhuma responsabilidade por ela.

A aceitação de que o transporte é um negócio pode também ser exemplificado com o transporte alternativo, visto como uma forma de ganhar a vida.

O usuário, premido pelas circunstâncias, pelo aparato ideológico e pelo histórico dos transportes coletivos, acaba perdendo a noção de que o transporte é mobilidade e, portanto, permite ou não o acesso a toda a cidade e, consequentemente, sua mobilidade social. Aceita que o transporte tal como é, ou sua ausência, sejam segregadores e limitadores do acesso à fruição da cidade.

Finalmente, o usuário também acaba por aceitar como absolutamente natural que o transporte coletivo seja diferente da educação, da saúde e da educação públicas, bem como da coleta de lixo, e deve ser pago por ele no ato de sua utilização e não indiretamente como aqueles, financiados que são pelos impostos e taxas.

\section{O AUTOMÓVEL}

A mobilidade nas cidades e metrópoles do mundo contemporâneo está ligada ao automóvel. No Brasil a implantação da indústria automobilística na década de 1960, a torna uma das principais fontes de crescimento do país, em termos econômicos. A produção nacional e tudo que daí decorre ficou crescentemente dependente desse setor industrial. Além do produto em si, ela tem um enorme efeito para trás, na demanda por outros setores, como, aço, autopeças, vidro, borracha, plásticos, tintas e vernizes, tecidos e couros etc. Além disso, demanda serviços de venda e pósvenda, oficinas de manutenção, comércio de peças de reposição, seguros, propaganda. Basta percorrer as cidades brasileiras e verificar nas ruas o número de estabelecimentos que giram em torno dessa indústria, além da propaganda e da publicidade, que ocupam enormes espaços na mídia. É imenso o número de pessoas que têm sua sobrevivência dependente dessa indústria. Acrescente-se mais recentemente a indústria de motos, com características semelhantes.
O automóvel mudou a face $e$ as características urbanas das cidades, que acabaram por depender cada vez mais dele. Expulsou, de maneira impiedosa e perversa, outros meios, como bondes e bicicletas. A cidade de São Paulo, por exemplo, possuía uma rede de bondes (hoje chamados de Veículo Leve sobre Trilhos (VLT)) que permitia 700 quilômetros de itinerários, com oferta de 0,58 viagem por habitante/dia. Mais do que as 0,22 viagem por habitante/dia hoje oferecida pelo metrô e pelos trens de subúrbios! Essa rede foi literalmente enterrada no final dos anos 1960 e coberta de asfalto para dar lugar aos automóveis (BRANCO, 2010).

A hegemonia do automóvel é total nas cidades brasileiras. Num olhar se vê a diferença de tratamento dado ao viário destinado quase que exclusivamente aos veículos individuais motorizados e às calçadas dos pedestres. Interessante notar que a manutenção das vias de trânsito para veículos motorizados é de responsabilidade das prefeituras e que a manutenção das calçadas para pedestres é responsabilidade do proprietário do imóvel à sua frente. Imagine-se o oposto, o que seria? Ruas esburacadas, com degraus, rampas elevadíssimas etc., e calçadas em permanente manutenção e conservação!

Cada vez mais o automóvel é o sonho de consumo, supostamente libertador do tormento do deslocamento por transportes coletivos de má qualidade, sem conforto e caros, e tanto mais sonho quanto mais dele, automóvel, se depende. Além disso, é considerado o salvador da economia nacional em momentos de crise.

Desprezem-se os monumentais congestionamentos por eles causados, do apetite insaciável por mais e mais espaço viário, da agressão à qualidade do ar pelas emissões de poluentes e material particulado, do estresse nosso de cada dia no trânsito e dos acidentes que, por exemplo, em São Paulo, o transporte individual motorizado causa. Em consequência de parte desses acidentes, praticamente dois motociclistas são mortos por dia. Motociclistas, vulgo motoqueiros que, devido aos congestionamentos provocados pelos automóveis, são os que viabilizam a circulação de documentos e muitas mercadorias nas cidades.

São Paulo tinha, no final da década de 1970, 14 mil quilômetros de vias e 965 mil veículos. Hoje tem 17 mil quilômetros de vias e 7 milhões de veículos, apesar dos gigantescos investimentos feitos em alargamentos de vias, viadutos e túneis. E está, obviamente, congestionada. Não há como atender a demanda viária dessa frota gigantesca.

No entanto, se os níveis de subsídio ao transporte coletivo são baixíssimos com mostrado anteriormente, o subsídio escondido e/ou o pagamento indireto via impostos nas melhorias feitas em benefício do transporte individual motorizado, foi e é gigantesco. Assim acontece com os enormes investimentos em sistema viário, viadutos, túneis, 
na sinalização viária, operação e fiscalização, na desnecessária largura das vias para acomodar estacionamento de veículos, isenções de Imposto sobre Produtos Industrializados (IPI), subsídio em combustíveis para citar alguns exemplos.

Exemplo da hegemonia do automóvel: entre 2000 e 2010 a frota passou de 5 para 7 milhões. A frota de motos subiu $136 \%$ entre 2000 e 2008. A frota de ônibus coletivo permaneceu estável! (PUJANÇA..., 2011). Tudo isso esquecido, vale a pena lembrar que a indústria automobilística é uma vencedora nos termos de nossa sociedade fortemente competitiva. Ela tem um produto aperfeiçoado continuamente, incorporando novas tecnologias e contando com vários requintes de acabamento, com desempenho cada vez melhor e confiabilidade crescente. A renovação incessante dos modelos, provocando a obsolescência forçada, gera uma sempre crescente renovação da frota. Ela garante a qualidade de seu produto por prazos cada vez maiores. Logrou, sem entrar no mérito dos métodos usados, transformar as cidades e torná-las dependentes do seu produto. Trabalhou no plano imaginário e transformou o automóvel em um sonho de consumo, de liberdade, de aventura, de conforto, segurança e alegria familiar. Viabilizou formas de financiamento e crédito para garantir a fácil comercialização do produto. Trabalhou e trabalha no plano institucional de modo a garantir investimentos e políticas que beneficiem o seu produto, tornando-o crescentemente necessário.

Em resumo, a indústria automobilística associada às indústrias petroleira e imobiliária, configurou as cidade e metrópoles contemporâneas.

De outro lado, os transportes coletivos fazem a vez dos perdedores. Seu serviço é considerado de baixa qualidade, caro, ineficiente no atendimento da demanda. Os ônibus urbanos são ruidosos, grande número deles montado em chassis de caminhão, poucos com câmbio automático, design interior com muito desconforto, altura de degraus de acesso muito elevada na maioria dos casos, raríssimo uso de ar-condicionado e assim por diante. Metrôs com até 10 a 11 passageiros por metro quadrado nos horários de pico. É o imaginário oposto do transporte individual. Diante disso e principalmente no que se refere aos ônibus municipais, o usuário, assim que puder, migrará para o transporte individual motorizado. Em resumo, o automóvel é sonho de consumo, o transporte coletivo é pesadelo.

\section{A UNIVERSALIDADE}

O transporte coletivo ao deixar de ser uma questão política por força do aparato ideológico que o cunhou como negócio, se transforma em questão técnica e gerencial. Especialistas são chamados para resolvê-lo. As soluções são sempre apresentadas pelo viés técnico outecnológico. Linhas tronco-alimentadas, corredores exclusivos, rede de terminais, BRT (Bus Rapid Transit), VLT, Monorail, são apresentados como soluções mágicas e disputam os investimentos públicos cada um dizendo-se o mais conveniente. Mas não enfrentam, frequentemente, as questões políticas básicas. Não que não caibam como técnicas, mas tudo leva à necessidade de mais investimentos, e quase nunca se fala nos custos para o usuário, na tarifa. Lembremos que um transporte tem a qualidade proporcional à capacidade de pagamento de seus usuários. Se quisermos aumentar muito sua qualidade, poderá haver restrição no ritmo dos investimentos, dado a falta de receitas do poder público para isso, ou a tarifa poderá ser impraticável para o usuário. Será necessário subsidiá-la. Isso não é discutido. Quem pagará a conta pelo uso do serviço, não é objeto de discussão. A questão política se esfuma.

Tudo isso está incorporado socialmente e talvez até por parte dos leitores. Trata-se de um paradigma, que consiste nesse conjunto de concepções e valores repassados pelo aparato ideológico, pelo aparato jurídico e, até onde se saiba, ultrapassa as fronteiras classificatórias de direita ou esquerda. Certamente o pagar o transporte com a tarifa no ato de sua utilização deve ter uma grande quantidade de significados subjetivados, dentre outros, a questão da liberdade. Ter grande mobilidade sem pagar tarifa, sem dúvida, dá a sensação de liberdade e não só a sensação, é um fato. Mas em nossa sociedade, impor limites faz parte do aparato de controle e dominação.

A aprovação do transporte como direito social, antes apontado, pode significar uma nova possibilidade de discutir a questão da universalidade, superando-se a visão do transporte coletivo como um serviço a mercado, o que fica, por exemplo, plenamente explicitado no art. 176 do Código Penal quando trata de estelionato e outras fraudes:

Art. 176 - Tomar refeição em restaurante, alojar-se em hotel ou utilizar-se de meio de transporte sem dispor de recursos para efetuar o pagamento:

Pena - detenção, de 15 (quinze) dias a 2 (dois) meses, ou multa.

Parágrafo único - Somente se procede mediante representação, e o juiz pode, conforme as circunstâncias, deixar de aplicar a pena. (BRASIL, 1940).

É dentro desse conjunto de questões que a universalidade tem de ser compreendida. Como apontado na mesa de debates, não basta a universalidade na educação e na saúde, por exemplo. É necessário, na saúde, que o modode encarar o diagnóstico e o tratamento, não sejam, digamos, contaminados pelo uso excessivo de tecnologia ou de medicamentos por pressão dos interesses econômicos, bem como que a educação que não seja dividida em educação para pensar e a educação para trabalhar, com forte recorte classistae ideológico ou contaminada por interesses 
econômicos que giram em torno dos livros, apostilas e materiais escolares.

A plena efetivação do direito social e da universalidade, ou seja, os modos pelos quais se concretizam, precisam ser discutidos amplamente e ter formas de participação e intervenção da sociedade civil e dos movimentos sociais, para que não venham a ser apropriados por alguns segmentos da sociedade ou pela autoridade do estado.

No caso dos transportes e mobilidade, a universalidade, além do acesso universal sem o impeditivo da barreiratarifária, passa pelo estabelecimento do planejamento das linhas que nem sempre passará pela lógica do movimento pendular ou pelo menor custo submetido a uma suposta racionalidade a qualquer preço e que acaba punindo certos usuários, pois há ineficiências que são decorrentes da história da ocupação da cidade, fruto de anos e anos de especulação imobiliária, por exemplo. O mesmo se diga em relação a horários, padrões de conforto, avaliação da qualidade do serviço prestado etc., de modo a evitar os efeitos perversos da mobilidade, que foram apontados no início desse texto.

É interessante notar que a mobilidade é terreno fértil para o modo de participação e democracia direta, pois nela, a experiência cotidiana, a vivência desempenha papel importantíssimo e que, dificilmente poderá se apropriado, plenamente, pelos especialistas e técnicos, sobretudo na tradição autoritária e elitista de nossa sociedade.

Outra questão importante, de natureza essencialmente política, é a forma pela qual se dá o financiamento da universalidade, num país como o Brasil, onde os recursos para tanto são oriundos de uma política tributária absolutamente antidemocrática quando comparado como outros países ocidentais, pois pagam proporcionalmente mais impostos os que tem menor renda e menos os que tem maior renda. Assim, quem ganha até três salários mínimos, paga impostos correspondentes a cerca de $53 \%$ do seu rendimento e quem ganha mais de vinte e cinco salários mínimos paga cerca de $29 \%$, uma vez que o grosso da tributação se dá no consumo, e não na renda ou patrimônio. (LAVINAS, 2014).

Fica claro, então, que a questão da universalidade nos transportes públicos abrange uma enorme gama de questões, quase todas elas envolvendo fortes disputas políticas, algumas das quais destacamos nessa última parte do texto.

\section{AS DISPUTAS POLÍTICAS}

Para um novo, digamos, paradigma, e uma efetiva universalização dos transportes públicos e democratização da mobilidade urbana, é necessário ter em mente as principais características do atual que, recolocando, são:
1 - A concessão dos serviços de transportes urbanos e metropolitanos como uma atividade econômica que tem de apresentar características de negócio rentável e com garantias contratuais de equilíbrio econômicofinanceiro através da tarifa. Pela característica monoposônia desse serviço o resultado foi a cartelização e cartorialização do serviço, com empresas e grupos que dominam áreas ou cidades inteiras e em todo o país, há praticamente um século;

2 - A ideia de que o transporte coletivo deve ser centrado principalmente no deslocamento trabalho-residência-trabalho o que reflete uma visão apenas produtivista dos cidadãos, em detrimento de outras atividades proporcionadas pela vida urbana, atividades essas que dão o significado desse tipo de convivência e conduzem à efetiva cidadania (que vem da palavra cidade);

3 - A ideia, historicamente construída, de que o responsável pelo seu deslocamento é o próprio cidadão, e por isso deve pagar. Assim, a mobilidade deixa de ser percebida como algo essencial para o funcionamento pleno das cidades e passa a ser entendida como uma responsabilidade do cidadão. Tudo isso foi construído, provavelmente, após a separação da moradia do próprio local de trabalho, como nas colônias agrícolas e vilas industriais. Não por outra razão decorre a visão produtivista acima apontada;

4 - O endeusamento, via propaganda, do deslocamento motorizado e individual, decorrente do modelo de desenvolvimento fortemente centrado na indústria de automóveis e, mais recentemente, de motocicletas, e na indústria petroleira. Daí decorre uma priorização dos investimentos públicos para viabilizar esse padrão de deslocamento. Ao mesmo tempo instaura-se o modelo de ocupação imobiliária acoplado a esse modo de deslocamento, fechandose um círculo de descentralização perversa ou de adensamento também acoplado ao deslocamento individual motorizado. As cidades tornam-se então, cada vez mais dependentes do automóvel, em detrimento dos pedestres, ciclistas e esqueitistas.

5 - A abdicação do poder público de ser o efetivo dono do espaço viário do transporte público e outros modos de deslocamento, como pedestres, ciclistas etc., e, portanto de regulálos em benefício de todos, independentemente de sua condição de renda, necessidades especiais, etc. Daí a demonização do transporte público frente ao endeusamento do transporte privado. 


\section{CONCLUSÃO}

O entendimento dos transportes coletivos e sua universalidade, como questão política propicia que se abranjam praticamente todos os diversos aspectos e características de nossa sociedade, seus conflitos, suas ideologias, seus tabus e fetiches e as efetivas disputas políticas, frequentemente obscurecidas pelo aparato ideológico, pela grande mídia e pelos interesses dominantes.

Lembre-se que ao ser proposto o projeto denominado Tarifa Zero, em 1990, em São Paulo, qual seja, o pagamento indireto dos transportes coletivos municipais e que incluía uma reforma tributária fortemente progressiva, foi possível vivenciar todas as questões ideológicas e econômicas envolvidas. Desde a pronta desqualificação até o desvelar do que denomino joias do pensamento ideologizado, tais como os ônibus serão tomados por bêbados e desempregados; sendo gratuito haverá vandalismo, posto que não se valoriza o que é de graça; se é ruim pago, imagine de graça, haverá uso abusivo etc.. A reforma tributária proposta foi acusada de injusta para com os pobres inquilinos, prejudicial aos consumidores, pois haveria repasse aos preços etc. Algo de fazer inveja aos ultra conservadores.

Apesar disso, pesquisa realizada em dezembro de 1990 pela Toledo \& Associados mostrou que $76 \%$ dos entrevistados eram favoráveis ao projeto de transporte coletivos de ônibus, subsidiados pelo Imposto Sobre a Propriedade Predial e Territorial Urbana (IPTU) de imóveis mais valorizados. $67 \%$ queriam que os vereadores aprovassem o projeto Tarifa Zero.

Estudo sócio-econométrico prova que o sistema da Tarifa Zero "[...] possibilita modelos tributários mais justos e uma produção de transportes mais eficiente." (DIAS, 1991, p. 71). A Câmara sequer votou o projeto.

A cidade de Hasselt, na Bélgica, implantou a gratuidade em 1997. De 360.000 passageiros/ano em 1996, pulou para $1.498 .088,428 \%$ a mais em 97 após a gratuidade. Em 2008 foram 4.614.844 passageiros transportados, um crescimento de $1319 \%$ ! Segundo informações do site da cidade, diminuiu-se o orçamento em sistema viário e foi desnecessário executar um anel viário projetado".

Como consequência da crise europeia e pelo modo como se encaminham soluções para a crise, via austeridade e cortes em gastos públicos, o governo de Hasselt anuncia a volta de pagamento de um euro a partir de 2014. Comprova-se assim, que a política de subsídios está diretamente ligada à disputa de recursos do estado. Na crise europeia, nessa disputa leva a melhor, como se vê pó esse caso concreto, o capital financeiro.

Independentemente dessa crise, no relatório do Banco Interamericano de Desenvolvimento (BID) Cidades em Movimento de 2007 são citados exemplos de projetos técnicos e gerenciais na Colômbia, Curitiba, Zurique, Bangalore, Holanda. Nenhuma linha sequer sobre Hasselt.

O transporte coletivo com acesso universal, que seja instrumento de mobilidade social e estabeleça o primado da mobilidade coletiva em relação à mobilidade individual motorizada, é uma possibilidade e, mais do que isso, uma necessidade à luz de um mínimo de racionalidade frente ao caos provocado pelos crescentes congestionamentos, da poluição do ar, acidentes mortais já citados etc. Mas, como se viu pelos problemas a enfrentar, trata-se de uma luta árdua e fortemente politizada, com tudo o que isso significa.

As Jornadas de Junho de 2013 são um exemplo marcante do significado político da questão da mobilidade, do transporte e da tarifa. Os movimentos sociais e populares puxados pelo Movimento Passe Livre (MPL), mostraram de forma insofismável que tendo clareza na reivindicação e preparo para enfrentar o aparato ideológico dominante, a voz das ruas, a democracia participativa e direta são poderosos instrumentos de conquistas e transformações políticas e sociais.

\section{REFERÊNCIAS}

BANCO INTERAMERICANO DE DESENVOLVIMENTO. Cidades em movimento. Washington, D.C., 2007.

BRANCO, A. M. Bondes modernos. O Estado de São Paulo, São Paulo, p. 2, fev. 2010.

BRASIL. Presidência da República. Decreto-Lei $\mathrm{n}$. 2.848, de 7 de dezembro de 1940. Código penal. Diário Oficial da União, Brasília, DF, 1940.

DIAS, J. L. da S. Tarifa zero e eficiência no transporte coletivo urbano. Revista dos Transportes Públicos - ANTP, São Paulo, ano 14, n. 53, set. 1991.

DINIZ, D. Diversidade em trânsito. O Estado de São Paulo, São Paulo, p. 9, dez. 2013. Caderno Aliás.

LAVINAS, L. A long way from tax justice: the Brazilian case. Berlin: Global Labour University, 2014. Disponível em:<http://www.global-labouruniversity.org/fileadmin/GLU_Working_Papers/ GLU_WP_No.22.pdf>. Acesso em: 1 jan. 2016.

MAGALHÃES, G. Tarifa de ônibus em SP e Rio está entre as mais caras do mundo, diz estudo. Folha de São Paulo, São Paulo, 16 jan. 2015. Disponível em:<http://www1.folha.uol.com.br/ cotidiano/2015/01/1575811-tarifa-de-onibus-emsp-e-rio-esta-entre-as-mais-caras-do-mundo-dizestudo.shtml. Acesso em: 1 jan. 2016. 
PUJANÇA Enganadora. O Estado de São Paulo, São Paulo, mar. 2011. Disponível em:<http:// www.estadao.com.br/noticias/impresso, pujancaenganadora.690346,0.htm>. Acesso em: 1 jan. 2016.

SÃO PAULO. Governo do Estado. Secretaria de Transportes Metropolitanos. Diretoria de Planejamento e Expansão dos Transportes Metropolitanos. Pesquisa de mobilidade 2012 da Região Metropolitana de São Paulo: Sistema das Informações - Pesquisa Domiciliar. São Paulo, 2013. Disponível em:<http://www.metro.sp.gov.br/ metro/arquivos/mobilidade-2012/relatorio-sintesepesquisa-mobilidade-2012.pdf>. Acesso em: 1 jan. 2016.

Prefeitura. Municipalização dos ônibus na cidade de São Paulo. São Paulo,

ZILBOVICIUS, M.; GREGORI, L. Tarifa do transporte e o que está por trás dela. Carta Maior, ago. 2013. Disponível em:<http://www.cartamaior.com.br/?/ Editoria/Politica/Tarifa-do-transporte-o-que-estapor-tras-dela-/4/28451>. Acesso em: 1 jan. 2016.

NOTA

1 Ver mais informações no site Tarifazero.org na seção Boas Experiências.

Lúcio Gregori

Engenheiro civil

Doutor pelo Programa de Pós-Graduado em Mecânica

dos Fluídos da Escola Politécnica da Universidade de São

Paulo (POLI-USP)

E-mail: luciogreg@gmail.com

Universidade de São Paulo - USP

Av. Prof. Luciano Gualberto, travessa $3 n^{\circ} 380$, São Paulo/ SP

CEP: 05508-010 